\title{
Temporal Variation in Gas Temperature at the Atomization Stage in Several Types of Graphite Furnaces for Atomic Absorption Spectrometry
}

\author{
Tetsuya Ashino, ${ }^{* \dagger}$ Haruki Shimabukuro, ${ }^{* *}$ Shun Morimoto, ${ }^{*}$ and Kazuaki Wagatsuma* \\ *Institute for Material Research, Tohoku University, 2-1-1 Katahira, Aoba, Sendai 980-8577, Japan \\ **Ryukyu-Cement Co. Ltd., 2-2-2 Irizima, Urasoe, Okinawa 901-2023, Japan
}

\begin{abstract}
In order to compare and evaluate the atomization process occurring in several types of graphite furnaces for atomic absorption spectrometry, the authors estimated temporal variations in the gas temperature by using a two-line method under the assumption of a Bolzmann distribution. The atomization furnaces employed were a graphite tube, a graphite tube coated with pyrolitic carbon, a graphite tube with a platform and a graphite cup. Differences in the temporal variation in the gas temperature among these graphite furnaces were observed.
\end{abstract}

(Received April 3, 2009; Accepted August 11, 2009; Published October 10, 2009)

\section{Introduction}

Electrothermal atomic absorption spectrometry (ET-AAS) ${ }^{1}$ is extensively employed for the determination of trace amounts of elements in various application fields. The analytical advantages in ET-AAS are as follows: the apparatus is simple and less expensive. The running cost of analysis is low. Moreover, the detection sensitivity of several elements is better than that obtained by other analytical methods. Especially, ET-AAS combined with various chemical pretreatment procedures has been reported for the determination of ultra-trace elements in metallic materials. ${ }^{2-6}$

Regarding the analytical procedure in ET-AAS, a sample solution is injected into an atomization furnace. Then, this furnace, which is commonly made of graphite (graphite furnace), is electrothermally heated along with a suitable temperature program for each analyte element to be pre-determined for generating an atomic vapor to measure the atomic absorption. Several types of the graphite furnaces, including a graphite tube, ${ }^{1,7}$ a graphite tube coated with pyrolitic carbon, ${ }^{8,9}$ a graphite tube with a platform ${ }^{10}$ or a graphite cup, ${ }^{11,12}$ have been developed and actually employed for sensitive and precise determinations by AAS.

Accordingly, it is important to select a suitable temperature program for obtaining more precise and sensitive analytical values. In commercial ET-AAS apparatuses, a radiation thermometer or a thermocouple device is used to control the heating of the furnace with the temperature program. The temperature that is estimated with these measuring devices corresponds to the wall temperature of the graphite furnace; however, a gas temperature that represents the atomic vapor of the analyte element in the furnace cannot be obtained with these devices. It is considered that the gas temperature is a prime, important factor for controlling the atomization process occurring in the atomization furnace. Therefore, a procedure

† To whom correspondence should be addressed.

E-mail: ayustet@imr.tohoku.ac.jp for monitoring the gas temperature in the graphite furnace is required.

It is difficult to measure transient variations in the atmosphere temperature in a graphite furnace by using a radiation thermometer or a thermocouple device. It is however expected that spectroscopic methods can be applied to obtain such information during heating of the graphite furnace, due to their ability of remote sensing as well as rapid response. A two-line method can provide a gas temperature under a local thermodynamic equilibrium condition. ${ }^{13}$ Then, variations in the gas temperature can also be monitored during the atomization process occurring in the graphite furnace. ${ }^{14}$

In order to estimate the gas temperature in the atomization furnace directly, the authors have reported a monitoring system by using a two-line method. ${ }^{15}$ In the developed method, iron was selected as a probe element. The gas temperature was observed by using two iron atomic lines assigned to the $3 d^{6} 4 s-3 d^{5} 4 s 4 p$ transition. Each atomic absorbance was monitored and then converted into a characteristic temperature under the assumption of the Bolzmann distribution. In the present work, the authors investigated temporal variations in the gas temperature during the atomization process when several types of the graphite furnaces were employed.

\section{Experimental}

\section{Apparatus}

A Z-9000 (Hitachi Corp., Japan) simultaneous multi-element atomic absorption spectrometer with an auto-sampler system was employed. As a light source, a hollow-cathode lamp (Hamamatsu Photonics Corp., Japan) was used. The operating conditions for the measurement by the Z-9000 are listed in Table 1. The types of the atomization furnaces employed were as follows: a graphite tube, a graphite tube coated with pyrolitic carbon, a graphite tube with a platform and a graphite cup (Hitachi Corp., Japan). These furnaces are abbreviated as graphite tube, pyrolitic carbon tube, platform and cup, respectively. 
Table 1 Instrument and operating condition

\begin{tabular}{|c|c|c|}
\hline Instrument & \multicolumn{2}{|c|}{$\begin{array}{l}\text { Hitachi Z-9000 multi-element } \\
\text { atomic absorption spectrometer }\end{array}$} \\
\hline Wavelength & \multicolumn{2}{|l|}{372.0 and $373.7 \mathrm{~nm}$} \\
\hline Light source & \multicolumn{2}{|c|}{ Hollow cathode lamp } \\
\hline Lamp current & \multicolumn{2}{|l|}{$5.0 \mathrm{~mA}$} \\
\hline Ar gas flow rate & \multicolumn{2}{|c|}{$0.2 \mathrm{~L} \mathrm{~min}^{-1}$ (without atomization stage) } \\
\hline \multirow[t]{2}{*}{ Injection volume } & $20 \mu \mathrm{L}$ & \\
\hline & Temperature/K & Time/s \\
\hline Drying & $353-423$ & 30 \\
\hline Charring-1 & $423-1373$ & 30 \\
\hline Charring-2 & 1373 & 30 \\
\hline Atomizing & $X$ & 10 \\
\hline Cleaning & 3273 & 10 \\
\hline
\end{tabular}

$X=2573,2773$ or 2973.

Ramp time of atomizing: $0.6-0.8 \mathrm{~s}$.

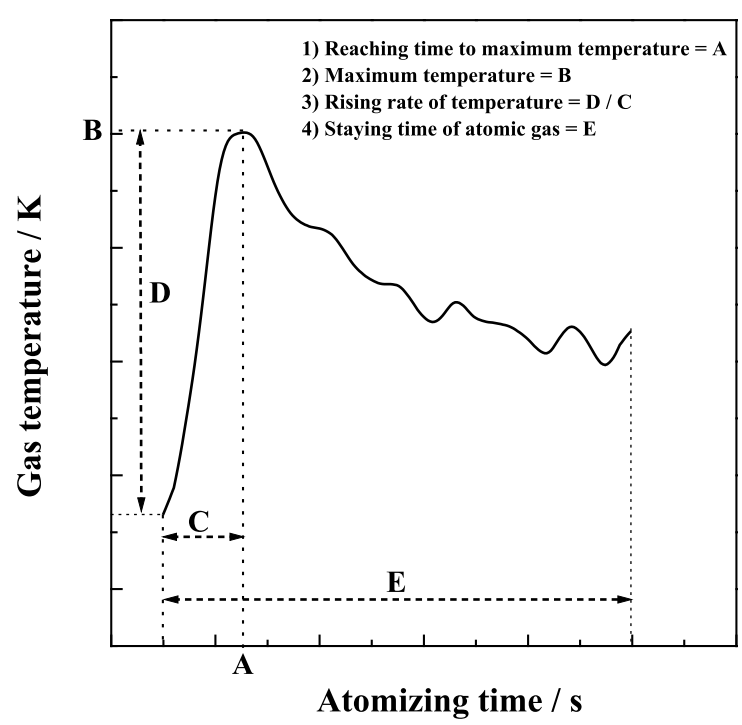

Fig. 1 Variation of the gas temperature at the atomization stage.

\section{Reagents and procedure}

An iron stock solution $\left(1.0 \mathrm{~g} \mathrm{~L}^{-1} ; 100 \mathrm{mg}\right.$ of metallic iron (Mairon HP, Toho Zinc Co. Ltd., Japan)) was dissolved in $7 \mathrm{~mol} \mathrm{~L}^{-1}$ of nitric acid and exactly diluted to $100 \mathrm{~mL}$ with water. The concentrations of iron sample solutions for measuring the gas temperature were as follows: $1.2 \mathrm{mg} \mathrm{L}^{-1}$ for the graphite tube and the cup, $0.24 \mathrm{mg} \mathrm{L}^{-1}$ for the pyrolitic carbon tube and $1.0 \mathrm{mg} \mathrm{L}^{-1}$ for the platform. The concentration range of iron, which was shown to have a linear correlation between the concentration and the absorbance, was respectively confirmed in all types of atomization furnaces. Then, the authors adopted that the concentration of the sample solution in this work was the highest in this range. ${ }^{15}$ These solutions were respectively prepared by diluting from the stock solution before use. The nitric acid used was an electronics industry grade (Wako Pure Chemical Industries Ltd., Japan), and deionized water (Yamato Scientific Co. Ltd., Japan) was used for all preparations of the sample solutions.

Two hollow cathode lamps were installed to monitor two different wavelengths of iron atomic lines simultaneously. The
Table 2 Characterization of the gas temperature in several types of atomization furnaces

\begin{tabular}{lcccc}
\hline Furnace & $\begin{array}{c}\text { Reaching } \\
\text { time to } \\
\text { maximum } \\
\text { temperature/ } \\
\mathrm{s}\end{array}$ & $\begin{array}{c}\text { Maximum } \\
\text { temperature/ } \\
\mathrm{K}\end{array}$ & $\begin{array}{c}\text { Rising rate of } \\
\text { temperature/ } \\
\mathrm{K} \mathrm{s}^{-1}\end{array}$ & $\begin{array}{c}\text { Staying time } \\
\text { of atomic } \\
\text { gas/ } \\
\mathrm{s}\end{array}$ \\
\hline $\begin{array}{l}\text { Graphite tube } \\
\begin{array}{l}\text { Pyrolitic } \\
\text { carbon tube }\end{array}\end{array}$ & 1.10 & 1218 & 1348 & 4.48 \\
$\begin{array}{l}\text { Platform } \\
\text { Cup }\end{array}$ & 1.10 & 1266 & 1739 & 2.16 \\
\hline
\end{tabular}

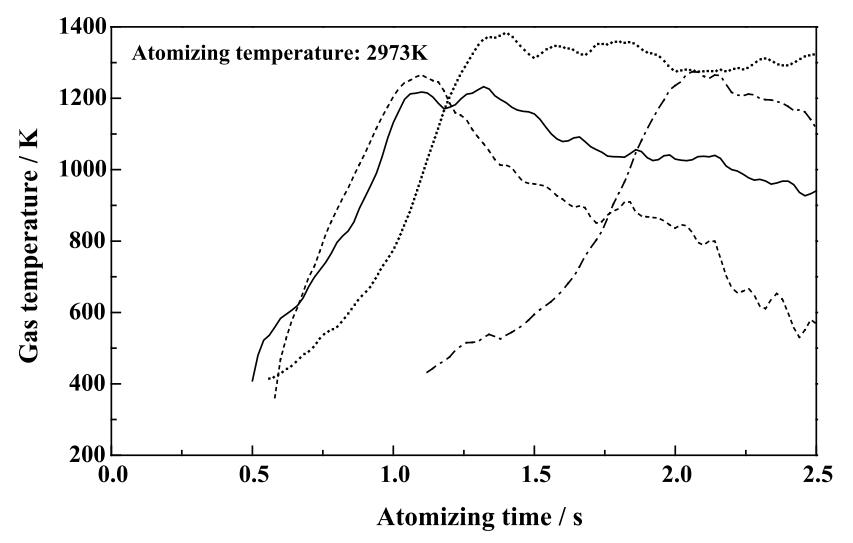

Fig. 2 Comparison of the variation in the gas temperature in several atomization furnaces. $\longrightarrow$, Graphite tube; --.----., pyrolitic carbon tube; -.-.-, platform; -........., cup.

absorbance of iron was then measured under the conditions listed in Table 1. The absorbance values for each spectral line were recorded on a personal computer through an AD converter. Finally, the temporal variations in the gas temperature were directly estimated by using the reported method, ${ }^{15}$ and then a variation profile, such as Fig. 1, could be obtained. The variations in the gas temperature are determined not only by the temperature distribution, but by the spatial distribution of iron atoms through their diffusion in the atomization stage. In other words, it reflects that the atomic gas generates at a center (high-temperature area) and moves to an edge (low-temperature area) of the furnace. Four parameter items shown in Fig. 1 were defined for characterizing the temporal variations in the gas temperature.

\section{Results and Discussion}

Temporal variation in the gas temperature by using different types of atomization furnaces

It is interesting to estimate the difference in the temporal variations of the gas temperature for four kinds of graphite furnaces. The characterization parameters for comparing the gas temperature are listed in Table 2, and each variation in the gas temperature in the range of the atomizing time between 0 and $2.5 \mathrm{~s}$ is shown in Fig. 2.

In all types of graphite furnaces, the maximum gas temperature obtained was almost similar and lower than the atomizing 
temperature pre-set in the instrument. However, differences in the characterization parameters for describing the variation in the gas temperature among the graphite furnaces were observed. Similar values of the reaching time to the maximum temperature were obtained, except for the platform. Moreover, the gas temperature in the pyrolitic carbon tube was elevated and fell most rapidly. However, the gas temperature in the platform was elevated and reached the maximum most slowly in all types of graphite furnaces, and then the staying time of the atomic gas was longer compared to the graphite tube and the pyrolitic carbon tube. On the other hand, the staying time of the atomic gas in the cup was the longest in all types of graphite furnaces.

The reason for these phenomena is considered to be the following. In the case of no platform plate, the charred sample is directly atomized by conductive heat from the wall, because it is in contact with the inner wall of the furnace. It can be further considered that the efficiency of the atomization process on the surface of a furnace coated with pyrolitic carbon is better than that on a surface of ordinary graphite. A possible reason for a rapid decrease of the gas temperature in a pyrolitic carbon furnace is that the sampling amount is smaller than that for the other types of furnaces. In this case, the atomic gas generates and moves from the center to the edge of the furnace more rapidly compared with the other types. When using a platform plate, the temperature of the platform is more slowly elevated compared with the wall temperature, because it is heated by radiant heat. As a result, the high-temperature area in the graphite furnace would be more extended compared with that of the other types, because the platform is heated gradually and homogeneously. On the other hand, the atomic gas stays at the high-temperature area and diffuses slowly in the cup atomizer. It is thus indicated that the atomization process occurring in the atomization furnace is different among the types of furnaces, and that the shape of the graphite furnace is especially important for determining the characteristics of the gas temperature.

\section{Temporal variation in the gas temperature at different atomizing temperatures}

When the atomizing temperature is varied by changing the heating program of the instrument, the authors respectively measured the temporal variations in the gas temperature for four kinds of graphite furnaces. There are shown in Fig. 3.

In all types of graphite furnaces, the maximum gas temperature becomes higher with increasing the atomizing temperature. However, differences in characterizing the temporal variation in the gas temperature among the types of graphite furnaces were also observed in this investigation. In the tube furnace or the cup atomizer, similar values regarding both the rising rate of the gas temperature and the staying time of the atomic gas were obtained independent of changing the atomizing temperature. In the pyrolitic carbon tube, the gas temperature was elevated and fell more slowly at the lower atomizing temperature, whereas it is elevated and fallen more rapidly with increasing the atomizing temperature. In the platform, the rising rate of the gas temperature increased together with elevating the atomizing temperature, whereas the staying time of the atomic gas was similar when changing the atomizing temperature.

These phenomena could be explained by the difference in the reaction rate between the sample species and the furnace. The charred sample was reduced by carbon on the furnace at the initial step of the atomizing stage. The atomic gas was then generated and diffused in the furnace. In the tube or the cup atomizer (made of ordinary graphite), the injected sample solution could penetrate into the wall of the furnace due to its porous surfaces. Accordingly, the atomic gas was generated

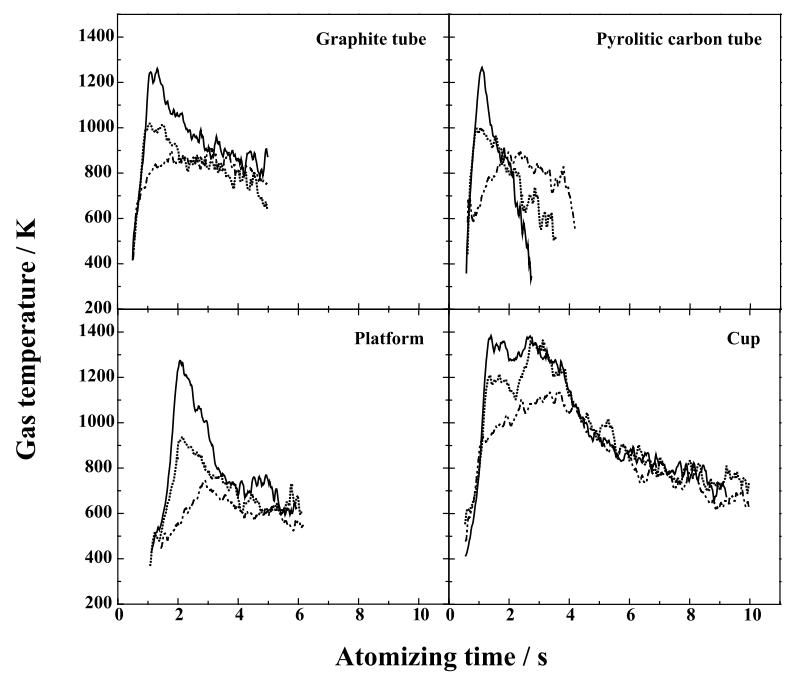

Fig. 3 Variation in the gas temperature in several types of atomization furnaces at different atomizing temperature. ——, $2973 \mathrm{~K}$; .............., $2773 \mathrm{~K}$; -...-..-., $2573 \mathrm{~K}$.

through two processes, which consisted of a reducing process within the furnace and an escaping process from inside of the furnace. The efficiency of the evaporation process of the atomic gas is less influenced by changing the atomizing temperature investigated $(2573-2973 \mathrm{~K})$. It is speculated that the reducing process is instantaneously completed, and therefore the escaping process is not influenced by changing the wall temperature of the furnace. However, in the pyrolitic carbon tube or the platform (made of glassy carbon), the injected sample solution could not penetrate into the wall of the furnace due to their non-porous surfaces. The efficiency of the evaporation process of the atomic gas would increase together with elevating the atomizing temperature, because the charred sample is directly heated and the atomic gas evaporates without the escaping process. Moreover, the atomic gas reaches the low-temperature area more rapidly together with increasing the efficiency of atomic gas evaporation in the pyrolitic carbon tube. It is therefore concluded that the influence of the atomizing temperature on the atomization process appears dominantly when changing the surface state of the graphite furnace.

\section{Conclusion}

The gas temperature was estimated by the two-line method using iron atomic lines. The gas atmosphere temperature at the atomization stage was much lower than the atomizing temperature in the temperature program of the instrument. This effect indicates a distinct difference between the wall temperature of the furnace and the atmosphere temperature.

In four kinds of atomization furnaces (graphite tube, the pyrolitic carbon tube, the platform and the cup), the gas temperature of iron was measured, indicating that the temporal variations of the gas temperature strongly depend on the type of atomization furnace. These phenomena could be explained from the atomization process in the furnace, which comprises the generation and retention of analyte atoms, particularly for each graphite furnace. 


\section{References}

1. H. Massman, Spectrochim. Acta, Part B, 1968, 23B, 215.

2. T. Ashino, K. Takada, and K Hirokawa, Anal. Chim. Acta, 1994, 297, 443.

3. T. Ashino and K. Takada, Anal. Chim. Acta, 1994, 297 , 443.

4. T. Ashino and K. Hirokawa, Anal. Sci., 1995, 11, 703.

5. T. Ashino and K. Takada, J. Anal. At. Spectrom., 1996, 11, 577.

6. T. Itagaki, T. Ashino, and K. Takada, Fresenius' J. Anal. Chem., 2000, 368, 344.
7. B. V. L'vov, Spectrochim. Acta, Part B, 1969, 24B, 53.

8. K. Kuga and K. Tsujii, Buseki Kagaku, 1978, 27, 441.

9. J. G. Sengupta, Anal. Chim. Acta, 1982, 138, 443.

10. B. V. L'vov, Spectrochim. Acta, Part B, 1978, 33B, 153.

11. H. Koizumi, K. Yasuda, and K. Katayama, Anal. Chem., 1977, 49, 1106.

12. K. Takada, Talanta, 1985, 32, 921.

13. P. W. J. M. Boumans, "Theory of Spectrochemical Excitation", 1966, Prenum Press, New York.

14. Y. Terui, K. Yasuda, and K. Hirokawa, Anal. Sci., 1991, 7 , 599.

15. H. Shimabukuro, T. Ashino, and K. Wagatsuma, Anal. Sci., 2008, 24, 1165. 